\title{
Evaluation and Optimization of Effective-dose of Alloxan for Inducing Type-2 Diabetes Mellitus in Long Evans Rat
}

\author{
Shaikh Shahinur Rahman, Nilufar Yasmin, Abu Taher Mohammad Mizanur Rahman, Akteruz zaman, \\ Mohammad Hafizur Rahman and Shakh Mohammad Abdur Rouf*
}

Department of Applied Nutrition and Food Technology, Islamic University, Kushtia, BANGLADESH.

\begin{abstract}
Background: The optimal effective and safe dose of alloxan for inducing stable diabetes in rats has been long arguable. Lower doses can result in auto-reversion from diabetogenic state to normal state. On the other hand, higher doses cause toxicity and loss of experimental animals since it completely destroys the insulin-producing pancreatic $\beta$ cells. Therefore, determination of effective as well as safe dose of alloxan to induce stable diabetes in experimental Long Evan rats is crucial for investigating on diabetes. Objective: To determine effective and safe dose of alloxan for inducing a stable diabetes mellitus in Long Evans Rats to facilitate availability of diabetic rats for studying on diabetes. Methods: Healthy adult Long Evans rats (80-156 g) were divided into eight groups and each group contains six rats. One group treated as a nondiabetic control (C) while the other seven groups (Group-2 to Group-8) were used as experimental diabetic groups. Different doses of alloxan (80,100,120,130,140, 150 and $160 \mathrm{mg} / \mathrm{kg}$ body weight) were injected through intraperitoneal routes in overnight fasting group- 2 to group-8 rats respectively. Blood glucose levels were monitored before and after administering alloaxan dose (for 7 consecutive weeks) by using a blood glucose meter and test strips. Results: In the case of non-diabetic rats, the normal blood glucose levels were found between 7.75 to $10.8 \mathrm{mmol} / \mathrm{L}$. On the other hand, a slow gradual increment of blood glucose levels were measured among the rats (group-2, group-3 and group-4) treated with low doses of alloxan $(80,100$ and $120 \mathrm{mg} / \mathrm{kg} \mathrm{BW})$ until 5 weeks. However, the increased blood glucose levels were reverted back to its normal by the following two weeks. Group-5 and Group-6 rats treated with alloxan doses of $130 \mathrm{mg} / \mathrm{kg}$ and $140 \mathrm{mg} / \mathrm{kg}$ respectively stably increased blood glucose levels during the experimental periods. While rats in group-7 and group-8 (treated with 150 and $160 \mathrm{mg} / \mathrm{kg} \mathrm{BW}$ ) were expired by the experimental period might be due to severe alloxan toxicity. Group- 6 rats treated with $140 \mathrm{mg} / \mathrm{kg}$ alloxan were more preferable because the diabetic level is much more stable and significant than group-5. Conclusion: The optimum effective dose of alloxan was found to be $140 \mathrm{mg} / \mathrm{kg}$ BW for induction of stable diabetes in Long Evan rats.
\end{abstract}

Key words: Alloxan, Diabetes mellitus, Long Evans Rat, induced diabetes, Toxicity.

\section{INTRODUCTION}

The incidence of diabetes mellitus is increasing day by day and assuming epidemic proportion in all over the world. To treat and manage the disease, newer and better drugs or diets are always investigated. The use of experimental induced diabetes rats remains as one of the easiest and convenient way for screening of new anti-diabetic drugs nutraceuticals. Chemical agents such as streptozotocin (STZ), alloxan etc are commonly used to induce diabetes in experimental animals for the research works. Although streptozotocin (STZ) is most commonly used chemical agents for induction of diabetes in rats ${ }^{1}$, there are severe disadvantages also reported by several groups., ${ }^{2,3}$
Submission Date: 19-05-2017; Revision Date: 28-06-2017; Accepted Date: 04-10-2017

DOI: $10.5530 / i j p e r .51 .4 s .96$ Correspondence: Dr. Shakh M A Rouf, Department of Applied Nutrition and Food Technology, Islamic University, Kushtia, BANGLADESH.

Phone no: +88-01718-852813 Email: abdurrouf_7@yahoo. com

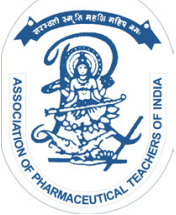

www.ijper.org 
The most important disadvantage of using STZ has been reported that the spontaneous recovery from high blood glucose levels by the development of functioning insulinoma. ${ }^{2,3,4}$ Higher incidence of kidney and liver tumours are also reported. ${ }^{4}$ Therefore, alloxan (2,4,5,6pyrimidinetetrone) which is the second most commonly used chemical for induction of diabetes mellitus ${ }^{5}$ because of its low cost and easy availability. Alloxan is routinely used in experimental animals ever since its ability to induce diabetes ${ }^{6}$ because it exerts specific effects on $\beta$-cells of pancreas leading to complete inhibition of pro-insulin biosynthesis. ${ }^{7}$ The dose of alloxan required to induce diabetes depends on the experimental animals and their species, route of administration and nutritional status. ${ }^{8}$ Diabetes mellitus with different degrees of severity can be produced by varying the doses of alloxan. The range of the diabetogenic dose of alloxan has been recognized to be quite narrow and even light overdosing may be generally toxic causing the loss of many animals. ${ }^{9}$ Kidney/tubular necrosis due to the toxic effects of the higher doses of aldrugloxan has been suggestive as a cause of animal loss. ${ }^{10}$ It has been reported that alloxan rapidly and selectively accumulated in the pancreatic beta cells. ${ }^{11,12}$ and induced DNA strand breaks in isolated rat pancreatic islets. ${ }^{13}$ The induction of lesion by administering drug in experimental animals is proportional to the dose. ${ }^{14}$ Therefore, the most important thing to keep in mind while using alloxan for inducing type-2 diabetes is the selection of optimum and nonlethal alloxan dose. Various doses of alloxan for inducing diabetes in many experimental animals have been reported. ${ }^{15,16,17}$ However, the optimal effective and safe doses of alloxan for inducing stable diabetes in rats are arguable. Moreover, due to the heterogeneity of diabetic conditions in man, no single animal model is entirely representative of a particular type of human diabetes. This is why many different animal models have been used to display different scenario of human diabetics. ${ }^{18,19,20}$ Reasonably, as an experimental model animal for studying human diseases, rat models have the advantages over mice and other model organisms because of obtaining higher volume of blood and tissue samples. Especially, in case of diabetes, the rat model behaves more likely to the human in many important ways, including the ability of environmental agents (e.g. toxins, stress, diet, drugs, vaccination etc.) to modify the disease. ${ }^{21}$ Although Long-Evans rat model is one of the most commonly used rat strain for studying many diseases including diabetes, however, to the best of our knowledge, no data yet to be published regarding optimum alloxan dose for inducing stable diabetes in Long Evan rats to study various parameters. Therefore, it is essential to determine the effective and safe dose of alloxan for inducing a stable type-2 diabetes mellitus in Long Evans rat with minimal drug toxicity. The object of the present study was to evaluate the effective and optimum alloxan dose for inducing a stable diabetes mellitus in Long Evans rat. Thus, researchers may have novel technique to induce stable diabetes in experimental Long-Evans rat for further study.

\section{MATERIALS AND METHODS}

\section{Chemicals}

All the chemicals were of analytical grade and obtained from commercial source as indicated: Alloxan monohydrate from Alfa Acer Johnson Company Great Britain and Blood Glucose determination kit Glucosure strips from Apex Bio, Taiwan.

\section{Experimental Animals}

Healthy mature Long-Evans rat having bodyweight ranging from 80 to $156 \mathrm{~g}$ were brought from animal's house of ICDDR ' $\mathrm{B}$ for the present study. The animals were acclimatized to standard laboratory conditions (temperature $24 \pm 1^{\circ} \mathrm{C}$, relative humidity $55 \pm 5 \%$ ) and a $12 \mathrm{~h}$ photoperiod in suspended wire meshed galvanized cages for one week before the commencement of the experiment. During the entire period of study, the rats were supplied with a semi-purified basal diet and water ad libitum.

\section{Induction of Diabetes and Study Design}

Alloxan monohydrate (Sigma Aldrich, St. Louis, MO, US $A$; stored at $4^{\circ} \mathrm{C}$ ) was dissolved in normal saline at room temperature and was injected by intraperitoneal routes in overnight fasted rats. The rats were divided into eight groups and each group consisted of six rats: one non-diabetic control and seven experimental groups. Randomly selected healthy adult overnight fasted Long Evans rats in group-2 to group- 8 were injected with different doses of alloxan (80, 100, 120, 130, 140, 150 and $160 \mathrm{mg} / \mathrm{kg}$ body weight respectively). After $72 \mathrm{~h}$, fasting blood glucose (FBG) levels of each rat were determined by collecting blood trough tail puncturing with Accuchek glucosure strips (Roche Diagnostics). Rats having FBG $\geq 200 \mathrm{mg} / \mathrm{dl}$ were considered as diabetes. Thereafter, FBG were determined at day 3, 7, 14, 21, $28,35,42$ and 49 to see the status of induced diabetes. Body weight, food and water consumption were also recorded regularly to justify the determined FBG. The Institutional Animal Ethics Committee approved the experimental protocol. 


\section{Statistical analysis}

Data from the experiments were analyzed using SPSS software for windows version 11.5. All results were expressed as the mean $\pm \mathrm{SD}$. One-way analysis of variance (ANOVA) used and paired or unpaired t-test was done to see any difference between groups.

\section{RESULT}

As shown in Table 1 the fasting blood glucose (FBG) level in control rats (Group-1) were found to be gradually increased ranging from $7.75 \pm 0.77$ to $10.8 \pm 0.42$ during the study period. The average increments of the FBG levels of rats in control group (Group-1) as shown in Table 2 were found to be in between 0.825 to $3.0 \mathrm{mmol} / \mathrm{L}$. The fasting blood glucose levels $(\mathrm{mmol} / \mathrm{L})$ in control rats were found to be increased gradually in parallel to their growth as compared with the beginning FBG to the next successive week`s FBG during the study period. Among the alloxan injected rats (Group-2 to Group-5) FBG levels were mildly increased when compared with that of respective rats before alloxan injection but did not induced diabetes. While, the increase of FBG levels among the rats of Group- 6 and Group-7 were found to be significantly increased at the end of the $1^{\text {st }}$ week after alloxan injection and induced diabetes. A Fasting Blood Glucose (FBG) level $\geq 10 \mathrm{mmol} / \mathrm{L}$ at the age $8^{\text {th }}$ weeks is considered as diabetes. All of the rats in Group- 8 injected with alloxan dose of $160 \mathrm{mg} / \mathrm{kg}$ body weight were expired by the $5^{\text {th }}$ day after injection. The FBG levels in the rats of Group-3 (100 mg/ $\mathrm{kg}$ alloxan dose) and Group-4 (120 mg/ kg alloxan dose) were slowly increased from $1^{\text {st }}$ to $4^{\text {th }}$ week $(\leq 10 \mathrm{mmol} / \mathrm{L})$ but from the end of the $4^{\text {th }}$ week the FBG levels were returning to the normal levels. The alloxan dose of $80 \mathrm{mg} / \mathrm{kg}$ body weight (Group-2), 100mg/kg body weight (Group-3) and $120 \mathrm{mg} / \mathrm{kg}$ body weight (Group-4) were unable to induce diabetes (Table 1 and Figure 1) throughout the study duration.

The average increments of FBG level in Group-2, Group-3 and Group-4 were found to be between 0.05 to $2.15,1.10$ to 3.30 and 0.80 to $2.80 \mathrm{mmol} / \mathrm{L}$ respectively (Table 2). The mean FBG levels of rats in Group-5 (130 mg/kg alloxan dose) were found to induce stable diabetes lately (after $2^{\text {nd }}$ week) and continued for the $6^{\text {th }}$ weeks. On the other hand, rats injected with $140 \mathrm{mg} /$ kg.b.wt (Group-6) were stably induced diabetes at the end of the $1^{\text {st }}$ week $(10.87 \pm 1.60)$ and the significant hyperglycemia was continued until the end of this study (Table 1). The average FBG levels increase among the rats in Group-5 were significant and found in between 1.775 to $12.32 \mathrm{mmol} / \mathrm{L}$. Whereas, the fasting blood glucose levels increment among the rats of Group-6 were most significant and were ranging from 3.575 to $22.65 \mathrm{mmol} / \mathrm{L}$ (Table 2 ). The FBG levels of rats in Group-7 (alloxan dose of $150 \mathrm{mg} / \mathrm{kg}$ b.wt.) were confirmed to develop diabetes at the end of the $1^{\text {st }}$ week (12.8 \pm 1.15$)$. However, the mean FBG levels were continuously and severely rising from 6.6 to 35.3 $\mathrm{mmol} / \mathrm{L}$ (Table 2) until the expiration. Among the Group-7, half of the rats were expired at the $4^{\text {th }}$ week and remaining was expired after the $5^{\text {th }}$ week may be due to severe toxicity of alloxan. Thus, $150 \mathrm{mg} / \mathrm{kg} \mathrm{b}$. wt or above doses of alloxan is not suitable for stable diabetes induction because it was heavily toxic and the diabetic rats might not be sustained for further studies.

\section{DISCUSSION}

Inductions of diabetes mellitus using chemicals such as Streptozotocin (STZ) or alloxan among the experimental animals including rats are commonly practiced

\begin{tabular}{|c|c|c|c|c|c|c|c|c|}
\hline \multirow{3}{*}{ Weeks } & \multicolumn{8}{|c|}{ Fasting Blood Glucose (FBG) mmol/L (Mean \pm SD) } \\
\hline & \multirow{2}{*}{$\begin{array}{l}\text { Group-1 } \\
\text { (Control) }\end{array}$} & \multicolumn{7}{|c|}{ Experimental rats injected with different doses of Alloaxn } \\
\hline & & Group-2 & Group-3 & Group-4 & Group-5 & Group-6 & Group-7 & Group-8 \\
\hline $\begin{array}{l}\text { Before alloxan } \\
\text { injection. }\end{array}$ & $7.75 \pm 0.77$ & $8.50 \pm 1.17$ & $6.80 \pm 1.27$ & $6.30 \pm 1.47$ & $7.13 \pm 1.09$ & $7.30 \pm 2.29$ & $6.20 \pm 1.02$ & $7.21 \pm 1.26$ \\
\hline $1 \mathrm{st}$ & $8.6 \pm 1.39$ & $8.8 \pm 1.17$ & $7.9 \pm 1.28$ & $7.1 \pm 1.42$ & $8.90 \pm 1.13$ & $10.87 \pm 1.60^{*}$ & $12.8 \pm 1.15^{*}$ & Expired \\
\hline 2nd & $8.8 \pm 1.15$ & $8.9 \pm 1.22$ & $10.1 \pm 0.79$ & $8.5 \pm 1.41$ & $11.53 \pm 0.95^{\star *}$ & $14.75 \pm 0.82$ & $21.2 \pm 3.02^{\star *}$ & - \\
\hline $3 r d$ & $9.1 \pm 0.94$ & $9.2 \pm 1.09$ & $9.3 \pm 1.42$ & $8.6 \pm 1.61$ & $13.78 \pm 0.99^{*}$ & $18.72 \pm 0.53^{*}$ & $26.8 \pm 3.09^{* *}$ & - \\
\hline 4th & $9.3 \pm 0.31$ & $9.9 \pm 1.49$ & $8.6 \pm 1.33$ & $9.1 \pm 1.72$ & $15.43 \pm 1.60^{* *}$ & $23.42 \pm 0.84^{*}$ & $34.1 \pm 4.64^{\star *}$ & - \\
\hline 5 th & $9.93 \pm 0.56$ & $7.0 \pm 0.88$ & $8.4 \pm 1.39$ & $7.8 \pm 1.59$ & $17.33 \pm 1.01^{* *}$ & $26.92 \pm 1.38^{*}$ & $41.5 \pm 5.50^{* *}$ & - \\
\hline 6th & $10.8 \pm 0.42$ & $6.6 \pm 0.91$ & $8.5 \pm 1.41$ & $7.6 \pm 1.59$ & $19.45 \pm 0.61^{* *}$ & $29.95 \pm 1.87^{*}$ & Expired & - \\
\hline
\end{tabular}

N.B.: * $p \leq 0.05 * * p \leq 0.001$ 


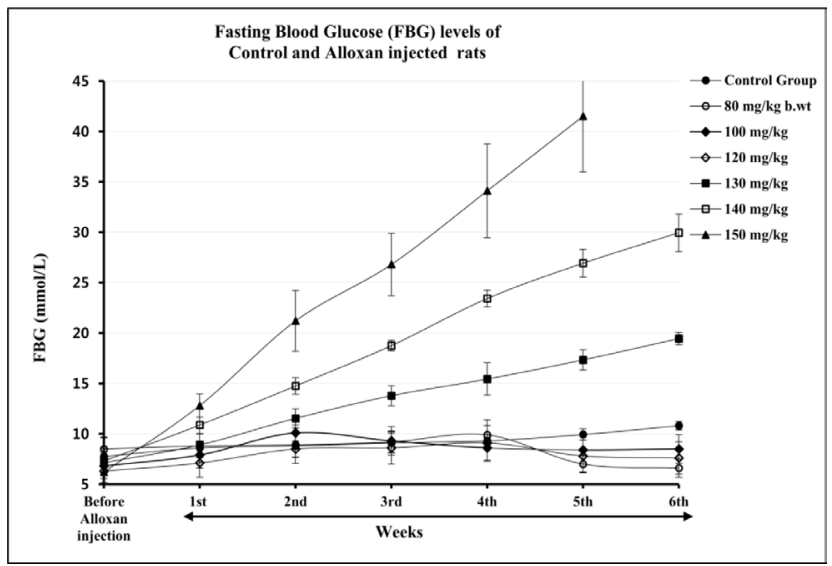

Figure 1: Fasting Blood Glucose (FBG) levels of Experimental rats.

for research purposes. Although sporadic information regarding the use of alloxan for inducing diabetes in experimental animals however, information about the effective and safe doses of alloxan for induction of stable diabetes in Long Evans rats is yet to be published. Diabetes mellitus is a metabolic disorder characterized by persistent hyperglycemia resulting from peripheral insulin resistance, hypoinsulinemia and/or finally $\beta$-cell dysfunction. ${ }^{22}$ Although streptozotocin is one of the most commonly used for induction of diabetes but it reported to have some disadvantages such as irreversible damage of the pancreatic $\beta$-cells, alloxan-induced diabetic model is preferable in recent years due to less toxicity and reversible damage of pancreas. ${ }^{2,3,4}$ For inducing diabetes in experimental animals, use of a low dose of alloxan ${ }^{23,24}$ has been reported earlier. A slide overdosing is highly toxic and may cause the loss of experimental animals. ${ }^{25,26}$ This study was investigated about the safe and effective doses of alloxan to induce stable diabetes in Long Evans rats. We injected six different doses of alloxan $(80,100,120,130,140,150$ and $160 \mathrm{mg} / \mathrm{kg}$ b.wt.) in 6 weeks age Long Evans rats through intraperitoneal route and investigated the diabetogenic effects for a period of consecutive six weeks. Among the control rats (Group-1) the fasting blood glucose (FBG) levels were found to increase from $7.75 \pm 0.77 \mathrm{mmol} / \mathrm{L}$ to $10.8 \pm 0.42 \mathrm{mmol} / \mathrm{L}$. The FBG increment is parallel with the body weight increment and may be due to higher food intake as well as lower glucose utilization efficiency compared with early adult stage. Very low doses $(80,100$ and $120 \mathrm{mg} / \mathrm{kg}$ b.wt) were unable to induce diabetes probably due to the sufficient dysfunction of the pancreatic $\beta$-cells. It should be noted here that low doses of alloxan may be altered pancreatic function so that the FBG levels gradually reduced even lower than the normal rats. Moderate doses $(130 \mathrm{mg} / \mathrm{kg}$ b.wt) of alloxan slowly induced diabetes and continued for the study period however, the severity of hyperglycemia is less than the optimum alloxan dose. We found that the $140 \mathrm{mg} / \mathrm{kg}$ b.wt alloxan dose most rapidly and significantly induced diabetes in Long Evans rats and maintained a continuous raised FBG levels until end of the study duration. In a previous study it was reported that the auto-reversal from frank diabetic state was found to occur with suboptimal alloxan doses (90-140 $\mathrm{mg} / \mathrm{kg}$ b. wt.). The reversal of hyperglycemia due to

\begin{tabular}{|c|c|c|c|c|c|c|}
\hline \multirow{2}{*}{ Group } & \multicolumn{6}{|c|}{ Average Increment of FBG Levels ( $\mathrm{mmol} / \mathrm{L}$ ) from the Beginning } \\
\hline & 1st Week & $2^{\text {nd }}$ Week & $3^{\text {rd }}$ Week & $4^{\text {th }}$ Week & $5^{\text {th }}$ Week & $6^{\text {th }}$ Week \\
\hline $\begin{array}{l}\text { Group-1 } \\
\text { (Control) }\end{array}$ & 0.825 & 1.075 & 1.375 & 1.500 & 2.175 & 3.000 \\
\hline $\begin{array}{c}\text { Group-2 } \\
\text { (Alloxan } 80 \\
\mathrm{mg} / \mathrm{kg} \text { ) }\end{array}$ & 0.050 & 0.150 & 0.450 & 1.150 & -1.750 & -2.150 \\
\hline $\begin{array}{c}\text { Group-3 } \\
\text { (Alloxan } 100 \mathrm{mg} / \mathrm{kg} \text { ) }\end{array}$ & 1.100 & 3.300 & 2.500 & 1.800 & 1.600 & 1.700 \\
\hline $\begin{array}{c}\text { Group-4 } \\
\text { (Alloxan } 120 \mathrm{mg} / \mathrm{kg} \text { ) }\end{array}$ & 0.800 & 2.200 & 2.300 & 2.800 & 1.500 & 1.300 \\
\hline $\begin{array}{c}\text { Group-5 } \\
\text { (Alloxan } 130 \mathrm{mg} / \mathrm{kg} \text { ) }\end{array}$ & 1.775 & $4.000^{* *}$ & $6.650^{*}$ & $8.300^{* *}$ & $10.20^{* *}$ & $12.32^{* *}$ \\
\hline $\begin{array}{c}\text { Group-6 } \\
\text { (Alloxan } 140 \mathrm{mg} / \mathrm{kg} \text { ) }\end{array}$ & $3.575^{\star *}$ & $7.450^{* *}$ & $11.425^{\star *}$ & $16.125^{\star *}$ & $19.625^{\star *}$ & $22.650^{* *}$ \\
\hline $\begin{array}{c}\text { Group-7 } \\
\text { (Alloxan } 150 \mathrm{mg} / \mathrm{kg} \text { ) }\end{array}$ & $6.600^{* *}$ & $15.000^{* *}$ & $20.600^{* *}$ & $27.900^{* *}$ & $35.300^{* *}$ & Expired \\
\hline $\begin{array}{c}\text { Group-8 } \\
\text { (Alloxan } 160 \mathrm{mg} / \mathrm{kg} \text { ) }\end{array}$ & Expired & - & - & - & - & - \\
\hline
\end{tabular}

N.B.: ${ }^{*} p \leq 0.05 * * p \leq 0.001$ 
pancreatic regeneration is early and common in case of alloxan treated in experimental rats. ${ }^{27}$ Mild variation of alloxan doses effects between present and previous study may be due to variation in experimental animals/ species as well as route of administration. While mild elevation of alloxan dose $(150 \mathrm{mg} / \mathrm{kg}$ b.wt.) could also rapidly induced diabetes but toxic enough to kill the rats. Further elevated dose $(160 \mathrm{mg} / \mathrm{kg}$ b.wt) caused prompt expiration of all the experimental rats most probably due to complete damage of the pancreas and other vital organs (data not shown). Alloxan acts by selectively destroying the pancreatic beta islets leading to insulin deficiency, hyper-glycaemia and ketosis resulting high mortality of experimental animals. ${ }^{28}$ and due to kidney tubular cell necrotic toxicity. ${ }^{11}$

\section{CONCLUSION}

Stable persistent diabetes in the experimental rats is must for studying anti-diabetic effects of various agents. The present will further enlighten the use of alloxan for inducing diabetes in Long Evans rats and other experimental animals.

\section{ACKNOWLEDGEMENT}

This research was supported by the Faculty of Science and Technology, Islamic University, Kushtia, Bangladesh. The authors are thankful to Chairman Professor. Dr. Md. Rezaul Karim for valuable suggestions and cooperation during research work.

\section{CONFLICT OF INTEREST}

The authors declare that there were no conflicts of interest regarding the publication of this manuscript.

\section{ABBREVIATIONS USED}

ICDDR'B: International Centre for Diarrhoeal Disease Research, Bangladesh; STZ: Streptozotocin; FBG: Fasting Blood Glucose; BW: Body weight; SD: Standard deviation; ANOVA: One-way analysis of variance; $\mathrm{mg} / \mathrm{kg}$ b. wt: milligram per kilogram body weight.

\section{REFERENCES}

1. Balamurugan AN, Miyamoto M, Wang W, Inoue K, TabataY. Streptozotocin (STZ) used to induce diabetes in animal models. J. Ethnopharm. 2003; 26:102-103.

2. Steiner $\mathrm{H}$, Oelz O, Zahnd G, Froesch E.R. Studies on islet cell regeneration, hyperplasia and intraminsular cellular interrelations in long lasting streptozotocin diabetes in rats. Diabetologia.1970; 6:558-564.

3. Yamagami T, Miwa A, Takasawa S, Yamamoto H. Introduction of rats pancreatic -B-cell tumour by the combined administration of streptozotocin or alloxan and poly (adenosine diphosphate ribose) synthetase inhibitors. Cancer Res.1985; 45:1845-1849.

4. Iwase M, Nnunoi K, WakisakaM, Kikuchi M, Maki Y, Sadoshima S, Fujishima M. Spontaneous recovery from non-insulin-dependent diabetes mellitus induced by neonatal streptozotocin treatment in spontaneously hypertensive rats. Metabolism.1991; 40:10-14.

5. Etuk EU. Animals models for studying diabetes mellitus. Agric Biol J N Am. 2010; 1(2):130-4.

6. Dunn JS, Sheehan HL,Mcletchie NGB. Necrosis of islets of langerhansproduced experimentally. Lancet.1943; 241:484-487.

7. Yamamoto $H$, Uchigata $Y$, Okamoto H.Streptozotocin and alloxan induce DNA strand breaks and poly (ADP-ribose) synthetase in pancreatic islets. Nature. 1981; 19; 294(5838):284-6.

8. Federiuk IF, Casey HM, Quinn MJ, Wood MD, Ward WK. Induction of type 1 diabetes mellitus in laboratory rats by use of alloxan; route of administration, pitfalls, and insulin treatment. Comprehensive Medicine. 2004; 54(3): 252-257.

9. Szkudelski T. The mechanism of alloxan and streptozotocin action in B cells of the rat pancreas. Physiol. Res. 2001; 50(6): 537-546.

10. Lenzen S, Tiedge M, Jornas A, Munday R. Alloxan Derivatives as a Tool for the Elucidation of the Mechanism of the Diabetogenic Action of Alloxan. In: Lessons from Animal Diabetes, Shafrir, E. (Ed.). Birkhauser, Boston, (1996). pp: 113-122.

11. Gorus FK, Malaisset WJ,Pipeleers DG. Selective uptake of alloxan by pancreatic B-cells. Biochem. J. 1982; 208: 513-5.

12. Elsner M, Gurgul-Convey E,Lenzen S. Relative importance of cellular uptake and reactive oxygen species for the toxicity of the alloxan and dialuric acid to insulin producing cells. Free. Radic. Biol. Med.2006; 41(5): 825-34.

13. Okamoto H. Molecular basis of experimental diabetes: Degeneration, oncogenesis and regeneration of pancreatic $\beta$-cells. BioEssays. 1985; 2(1):15-21.

14. McNeill JH. Experimental models of diabetes. Informa health care. 1990. $p-8$.

15. Bukhari SSI, Abbasi MHA, Khan MKA. Dose optimization of Alloxan for diabetes in albino mice. Biologia (Pakistan). 2015; 61(2):301-305.

16. Ashok DC, Shrimant NP, Pradeep MG, Akalpita UA. Optimization of Alloxan Dose is Essential to Induce Stable Diabetes for Prolonged Period. Asian Journal of Biochemistry. 2007; 2: (6):402.

17. Kastumata K, KastumataK Jr, Kastumata Y. Protectiv effect of diltiazem hydrochloride on the occurrence of alloxan-or streptozotocin-induced diabetes in rats. Horm. Metab. Res. 1992; 24(11):508-10.

18. Bergh AV, Vangheluwe $P$, VanderperA. Food-restriction in obese dyslipidaemic diabetic mice partially restores basal contractility but not contractile reserve. European Journal of Heart Failure. 2009; 11(12):1118-25.

19. VedtofteL, BodvarsdottirTB, GotfredsenCF, KarlsenAE, KnudsenLB, HellerRS. Liraglutide, but not vildagliptin, restores normoglycaemia and insulin content in the animal model of type 2 diabetes. Psammomysobesus. Regulatory Peptides. 2010; 160 :(1): 106-14.

20. Xiao J, Lin Y, Lin S. Cardiac protection by basic fibroblast growth factor from ischemia/reperfusion-induced injury in diabetic rats. Biological and Pharmaceutical Bulletin. 2010; 33(3):444-9.

21. Philip MI, Howard JJ .Rats!. Dis Model Mech. 2009; 2(5-6): 206-210.

22. Bangladesh Diabetic Somiti (BADAS) and World Diabetes Foundation (WDF). Mannual for Diabetes educators; 2009.

23. Venkatesh S, Reddy GD, Reddy BM, Ramesh M, Appa RAVN. Antihyperglycemic activity of Carullumaasttenuate. Fitoterapia. 2003; 74(3):274-9.

24. Virdi J, Sivakami S, Shahani S, Suthar AC, Banavalikar MM, Biyani MK. Antihyperglycemic effect of three of these extracts from Momordicacharantia. J. Ethnopharmacol. 2003; 88(1):107-11.

25. Gosh R, Sharatchandra K, Rita S,Thokchom IS. Hypoglycemic activity of Ficushispida (bark) in normal and diabetic albino rats. Indian J. Pharmacol. 2004; 36(4):222-5.

26. Arun N, Nalini N. Efficacy of turmeric on blood sugar and polyol pathway in diabetic albino rats. Plant Foods Hum. Nutr. 2002; 57(1): 41-52.

27. Jain DK, Arya RK. Anomalies in alloxan-induced diabetic model: It is better to standardize it first. Indian J Pharmacol. 2011; 43(1):91.

28. Rerup CC. Dugs producing diabetes through damage of the insulin secreting cells. Pharmacol Rev. 1970; 22(4):485-518. 
PICTORIAL ABSTRACT

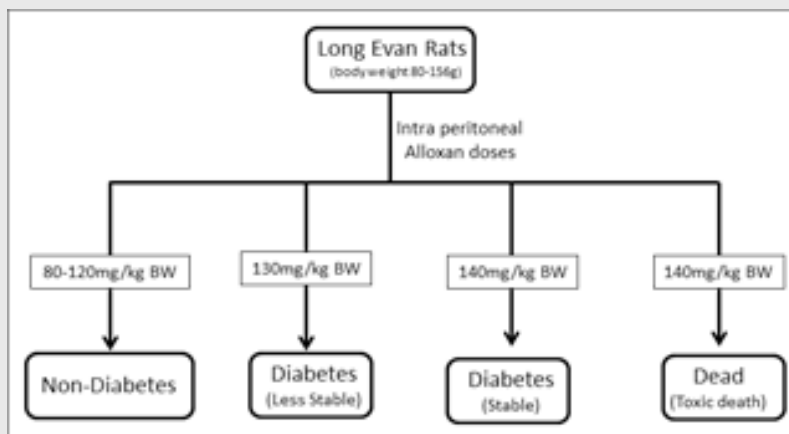

\section{SUMMARY}

- $\quad$ For in-vivo study with Induced type-2 diabetes mellitus long Evan rats is highly expected. STZ induction of diabetes mellitus was reported to be ineffective. Alloxan is a good alternative to the STZ. However, no concrete information about safe and effective Alloxan dose was found. Current study showed that an Alloxan dose of $140 \mathrm{mg} / \mathrm{kg}$ body weight is effective to induce stable type-2 diabetes mellitus in Long Evan Rat. This study will provide an effective conversion of normal Long Evan Rat to stable diabetic mellitus for further research on diabetes.

\section{About Authors}

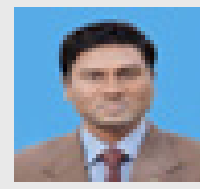

Shaikh Shahinur Rahman: Is presently working as Assistant Professor and is pursuing his Ph.D at the Department of Applied Nutrition and Food Technology, Faculty of Applied Science and Technology, Islamic University, Kushtia-7003, Bangladesh. He keeps his interest in the investigation of the functional foods and bioactive compounds, Nutritional biochemistry and Clinical nutrition.

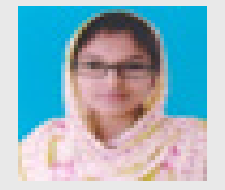

Nilufer Yasmin: She completed her Bachelor of Science from the Applied Nutrition and Food Technology, Islamic University, Kushtia, Bangladesh. Currently doing her M.Sc thesis on proximate composition analysis and it's hypoglycemic effects of Piper chaba the same department. Her research interests are molecular biology, functional foods and nutritional biochemistry.

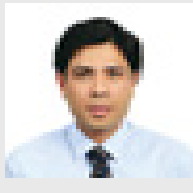

Abu Taher Md. Mijanur Rahman: He works as an Associate Professor in the Department of Applied Nutrition and Food Technology, Islamic University, Kushtia, Bangladesh. He received his Ph.D. degree in Food Engineering from Dongguk University, South Korea (August, 2015). His research interests are microencapsulation of enzymes, microorganisms and bioactive compounds; Biosensor; Solid-State Fermentation; Enzyme Kinetics; Food Microbiology; Food Chemistry; Biochemistry and Molecular Biology.

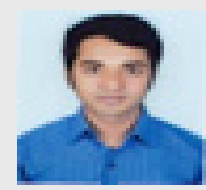

Aktaruzzaman: He has been achieved both of his Bachelor's Science and Master of Science degrees in Applied Nutrition and Food Technology from Islamic University, Kushtia, Bangladesh.

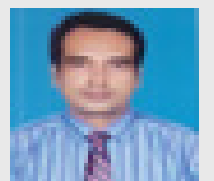

Md. Hafizur Rahman: He is presently working as Associate Professor at the Department of Applied Nutrition and Food Technology, Islamic University, Kushtia, Bangladesh. He keeps his interest in the field of Food engineering and technology, Nutritional Biochemistry and clinical nutrition. Pharmaceuticals, Food and Nutrition, Tropical food analysis, bioactive compounds etc.

Dr. Shakh M A Rouf: is currently working as a Professor in the Dept. of Applied Nutrition \& Food |Technology of Islamic University, Kushtia Bangladesh. He has been achieved his PhD from the Graduate School of Biomedical Sciences of Nagasaki University, Japan in 2013. His research topic was characterization of dipeptidyl peptidases (DPPs) from periodontal pathogen viz- $P$. gengivalis, $P$. endodontalis etc. Currently doing research on anti-diabetic effects of various endogenous fruits and plants, isolation and characterization of bacterial proteases, mechanism of antibacterial resistance from clinical isolates etc.

Cite this article: Rahman SS, N Yasmin, Rahman ATMM, Zaman A, Rahman MdH and Rouf SMA. Evaluation and Optimization of Effective-dose of Alloxan for Inducing Type-2 Diabetes Mellitus in Long Evans Rat. Indian $\mathrm{J}$ of Pharmaceutical Education and Research. 2017;51(4S):S661-S6. 